\title{
DE TOEPASSING VAN ISOTOPEN IN DE DIERPHYSIOLOGIE
}

\author{
DOOR \\ H. J. VONK \\ Laboratorium voor Vergelijkende Physiologie der Rijks-Universiteit Utrecht
}

Steeds meer wordt in de biologische en medische wetenschappen gebruik gemaakt van isotopen als hulpmiddel bij het wetenschappelijk onderzoek. In het hier volgend artikel wordt getracht, aan de hand van enige voorbeelden, een inzicht te geven in hetgeen met deze methode te bereiken is in de dierphysiologie. Beginnen wij met een definitie te geven van het begrip isotoop.

De chemische eigenschappen van een element worden bepaald door het aantal positieve ladingseenheden van de kern (overeenkomend met het aantal electronen dat om de kern wentelt). Dit aantal ladingseenheden is gelijk aan het aantal deeltjes met lading I en massa I (protonen), dat in de kern aanwezig is. De eenvoudigste kern, die van waterstof, bestaat uit slechts één proton. Behalve protonen komen in de kern der overige elementen echter ook ongeladen deeltjes van een massa I en lading o voor: de neutronen. Het atoomgewicht van het element is dus gelijk aan de som van het aantal protonen en het aantal neutronen van de kern.

Het totaal aantal deeltjes van de kern kan rechts boven naast het symbool van het element worden genoteerd, het aantal protonen (dus ladingseenheden) rechts onder. $\mathrm{He}_{2}^{4}$ duidt dan aan, dat de heliumkern bestaat uit 2 protonen en in totaal uit 4 deeltjes, zodat 2 neutronen aanwezig zijn. Voor de eerste rij van het periodiek systeem der elementen krijgt men de volgende notitie:

$$
\begin{array}{lllllllll}
\mathrm{He}_{2}^{4} & \left.\mathrm{Li}_{3}^{7}\right] & \mathrm{Be}_{4}^{9} & \mathrm{Bo}_{5}^{\mathrm{xr}} & \mathrm{C}_{6}^{\mathrm{x}} & \mathrm{N}_{7}^{\mathrm{x}} & \mathrm{O}_{8}^{\mathrm{r}} & \mathrm{F}_{9}^{\mathrm{x} 9}
\end{array}
$$

Het is echter gebleken, dat de bovenstaande combinaties der aantallen protonen en neutronen per kern niet de enig mogelijke zijn voor deze elementen. Voor een bepaald element ligt natuurlijk het aantal protonen vast (daar hiervan immers de chemische eigenschappen afhangen). Maar het aantal neutronen, dat daarnaast voorkomt, kan in (zeer) beperkte mate variëren. Zo komt in de natuuir naast de gewone waterstof $\left(\mathrm{H}_{\mathrm{z}}^{\mathrm{x}}\right)$ de $\mathrm{zg}$. zware waterstof $\left(\mathrm{H}^{2}\right)$ voor, die naast het proton nog één neutron bevat. $0.02 \%$ van alle waterstof is $z$ ware 
waterstof (ook aangeduid als $\mathrm{D}$, deuterium). Behalve $\mathrm{C}_{6}^{\mathrm{ra}}$ vindt men voor I.I $\% \mathrm{C}_{6}^{\mathrm{x}_{3}}$, behalve $\mathrm{N}_{7}^{\mathrm{x}_{4}}$ voor $0.368 \% \mathrm{~N}_{7}^{\mathrm{x}}$.

De verschillende vormen van éénzelfde element, die een verschillend aantal neutronen en dus een verschillend atoomgewicht hebben, worden de isotopen van dit element genoemd. Op enkele uitzonderingen na bestaan zij van alle elementen. Meestal overweegt één dezer isotopen zeer sterk in hoeveelheid. Nagenoeg al deze isotopen zijn stabiel, d.w.z. zij ontleden niet spontaan. Alleen onder de zwaarste elementen van het periodiek systeem zijn er die spontaan ontleden: de zg. radioactieve elementen (bv. Uranium, Radium, Thorium). Blijkbaar is er dus een grens van stabiliteit gesteld aan de reeks der elementen, daar meer gecompliceerde elementen dan het Uranium $\left(\mathrm{U}_{92}^{23^{8}}\right)$ in de natuur niet voorkomen.

Langs kunstmatige weg (door beschieting van kernen met snelle deeltjes) is men er in geslaagd ook van de lichtere elementen radioactieve (dus onstabiele) isotopen te maken. Zo zijn van koolstof de radioactieve isotopen $\mathrm{C}_{6}^{\mathrm{xx}}$ en $\mathrm{C}_{6}^{\mathrm{x}}$ gemaakt, van waterstof $\mathrm{H}_{13}^{3}$, van phosphor $\mathrm{P}_{15}^{32}$. Hun ontledingssnelheid is zeer verschillend (Vgl. blz. 509).

De isotopen van éénzelfde element hebben dezelfde chemische eigenschappen. $\mathrm{Zij}$ verbinden zich dus even gemakkelijk met een ander element en geven daarmee dezelfde combinaties. Daardoor zijn zij zeer moeilijk van elkaar te scheiden. Toch vertonen zij enig verschil in die eigenschappen, die afhangen van hun massa (atoomgewicht), zoals bv. in diffusiesnelheid. Daardoor wordt een scheiding - zij het met veel moeite - mogelijk.

Deze moeilijke scheiding is echter juist gunstig voor hun gebruik als onderzoekmiddel in de biologie. Door deze isotopen in te voeren in bepaalde verbindingen en dan deze verbindingen door een dier te doen opnemen (met het voer, het drinkwater, of door injectie) is het mogelijk de weg te volgen, die deze stoffen doorlopen, de plaats vast te stellen, waar zij tot andere stoffen worden verwerkt, de producten te vinden, waarin $z \mathrm{ij}$ worden omgezet.

Wil deze methode succes hebben, dan moet men allereerst weten, dat deze isotopen onschadelijk zijn voor het organisme. Dit werd door uitgebreide proefnemingen afdoende vastgesteld, althans voor de kleine concentraties waarmee men bij biologische proeven werkt.

Vender moet vast staan, dat de organen geen voorkeur voor of afkeer van bepaalde isotopen hebben. Ook deze voorwaarde is vervuld: de stabiele isotopen bv. komen in de uit een organisme geïsoleerde verbinding in dezelfde verhouding voor, waarin zij in de natuur voorkomen. Het $\mathrm{CO}_{2}$ van de lucht bevat in zijn koolstof I.I \% $\mathrm{Cl}^{13}$, voor de koolhydraten van het organisme geldt hetzelfde.

Men moet de isotopen in verschillende verbindingen kunnen inbrengen en ze daaruit weer kunnen isoleren. Dit geschiedt met de gewone hulpmiddelen der chemische synthese en analyse. Het isoleren uit verbindingen is nodig om de isotopen te kunnen bepalen. Want het is natuurlijk nodig te weten hoeveel 
van een isotoop in een ingebrachte verbinding aanwezig is en hoeveel dezelfde of eventueel een andere daaruit gevormde verbinding, die later uit het dier wordt geïsoleerd, bevat. Deze bepalingswijzen wijken enigszins af van de gewone middelen der chemie. Zware (stabiele) isotopen kunnen worden bepaa!d met de massaspectrograaf. In dit toestel laat men de in gasvormige verbinding gebrachte isotopen een baan beschrijven onder de invloed van electrische en magnetische krachten, waardoor het mogelijk is ze te scheiden en hun hoeveelheid vast te stellen uit de lading die zij veroorzaken op de plaats waar zij belanden. Massaspectrografen zijn zeer duur (tienduizenden dollars) en er wordt daardoor in Europa nog maar weinig mee gewerkt. In Amerika is er op grote schaal onderzoek mee verricht.

Voor de zware waterstof bestaat er gelukkig nog een ander hulpmiddel ter bepaling. Zware waterstof wordt nl. veel gebruikt in de vorm van zg. zwaar water en kan ter bepaling steeds door verbranding in die vorm gebracht worden. $Z$ waar water bestaat uit watermoleculen, waarin de twee $\mathrm{H}$-atomen vervangen zijn door zware waterstof. $\mathrm{Zijn}$ formule zou dus zijn $\left(\mathrm{H}_{2}^{2}\right\rangle_{2} \mathrm{O}$. Kortheidshalve schrijft men $\mathrm{D}_{2} \mathrm{O}$, daar $\mathrm{H}$ ook als $\mathrm{D}$ of d (deuterium) wordt aangeduid. Het gehalte aan zwaar water in een watermonster kan bepaald worden uit het soortelijk gewicht, daar dit voor zuiver $\mathrm{D}_{2} \mathrm{O}$ omstreeks $10 \%$ hoger is dan voor $\mathrm{H}_{2} \mathrm{O}$. Aangezien in de biologie steeds met vrij kleine concentraties $\mathrm{D}_{2} \mathrm{O}$ (0.I-3.0\%) wordt gewerkt moet deze bepaling zeer nauwkeurig geschieden en de daartoe gebruikte methodes zijn dan ook vrij subtiel, reeds omdat de meesten een temperatuurconstantie tot op $0.001^{\circ}$ gedurende de metingen vereisen. Op deze methoden kan hier niet verder wonden ingegaan ${ }^{1}$ ).

De concentratie der radioactieve isotopen wordt bepaald door het meten van hun straling. Meestal is dit $\beta$-straling, zoals bv. wordt uitgezonden bij de ontleding van radioactieve phosphor, die daarbij volgens de vergelijking $\mathrm{P}_{15}^{32} \rightarrow$ $\mathrm{S}_{16}^{32}+\beta_{-\tau}^{\circ}$ in zwavel overgaat. Deze straling wordt gemeten met een GeigerMüller teller. In principe is dit een metalen cylinder, waardoor een metalen draad is gespannen, die geisoleerd is van de wand. Tussen draad en wand is een potentiaal-verschil aangebracht. Dringt een $\beta$-deeltje in de cylinder door, dan ioniseert dit een deel van het daarin aanwezige (verdunde) gas. Hierdoor ontstaat tijdelijk een spanningsverandering tussen draad en omhulsel, die, na versterking met radiolampen, een telwerk doet verspringen. Zodoende kan men het aantal deeltjes, dat door een praeparaat (dat steeds op dezelfde plaats moet zijn opgesteld) in een bepaalde tijd wordt uitgezonden, tellen. Vooraf bepaalt men het o-effect van het toestel, d.i. het aantal deeltjes dat buiten aanwezigheid van het praeparaat, tengevolge van kosmische straling e.d. in de teller per bepaalde tijdeenheid doordringt. Dit wordt van de bepaling afgetrokken.

Wat hun zoölogische toepassing betreft zijn de isotopen allereerst te gebruiken bij het permeabiliteitsonderzoek. De wateropname van vissen en kik-

I) Zie b.v. VAN VeERSEN, Dissertatie Utrecht 1943 en lit. $\mathfrak{n}^{\circ} 8$ 
vorsen door kieuwen en huid, werd door het gebruik van zwaar water uitvoerig bestudeerd (Hevesy, KROGH) ${ }^{2}$ ). Tot dusverre kon men de snelheid van doorgang van zouten en andere opgeloste stoffen bestuderen door de concentratieveranderingen in milieu's van verschillende samenstelling na te gaan. Men kon die veranderingen zowel in het milieu als in de lichaamsvloeistof bepalen. Voor water was dit niet mogelijk, daar de concentratie daarvan zo groot is, dat kleine veranderingen daarvan niet konden worden vastgesteld. $\mathrm{D}_{2} \mathrm{O}$ biedt hiertoe nu een geschikt middel. Daar dit nagenoeg dezelfde eigenschappen heeft als water, kan uit de verplaatsing van $\mathrm{D}_{2} \mathrm{O}$ een conclusie worden getrokken omtrent de gelijktijdige verplaatsing van water. Bevat een afgesloten milieu, waarin zich een vis of kikvors bevindt, I $\mathrm{g} \mathrm{D} \mathrm{D}_{2} \mathrm{O}$ en $999 \mathrm{~g} \mathrm{H}_{2} \mathrm{O}$ en is in een bepaalde tijd o.I $\mathrm{g} \mathrm{D}_{2} \mathrm{O}$ uit het milieu verdwenen door opname in het dier, dan moet $99 \mathrm{~g}$ water gelijktijdig zijn opgenomen, omdat immers de kansen voor opname van $\mathrm{D}_{2} \mathrm{O}$-moleculen en van water-moleculen gelijk zijn. Men kan op deze wijze ook bepalen hoe snel een dier zijn totale watergehalte ververst. Neemt de concentratie aan $\mathrm{D}_{2} \mathrm{O}$ in het milieu niet verder af, dan heeft volkomen uitwisseling van het watervolume met het milieu plaats gehad. Uit de concentratievermindering van het buitenwater kan men, indien evenwicht bereikt is, op deze wijze afleiden hoeveel water zich in het dier bevindt en wanneer men dit nog weegt of zijn volume bepaalt, heeft men het watergehalte van het levende dier onder volkomen natuurlijke voorwaarden bepaald.

De belangrijkste toepassing hebben de isotopen echter gevonden op het gebied der stofwisseling. Met behulp van isotopen kan men de opbouwsnelheid van verbindingen nagaan, de plaats waar $z i j$ worden opgebouwd of afgebroken, eventueel de weg waarlangs hun opbouw en afbraak verloopt.

Om de opbouwsnelheid na te gaan, laat men dieren (ratten en muizen werden het meest gebruikt) enige tijd hongeren. Dan voedert men opnieuw. Met behulp van een injectie met $5 \%$ zwaar water en door verder de dieren gedurende de proef $3 \% \mathrm{D}_{2} \mathrm{O}$ als drinkwater te geven, bereikt men, dat het bloed en de lichaamsvloeistoffen een gehalte van I à I.5\% $\mathrm{D}_{2} \mathrm{O}$ krijgen gedurende het verloop van het experiment. $\mathrm{Bij}$ de opbouw van glycogeen, vet en eiwit, die na de hongerperiode plaats vindt, wordt (langs vele omwegen) de waterstof en dus ook de zware waterstof (D) van het lichaamswater in de opgebouwde verbindingen verwerkt. Isoleert men dus na verschillende tijden vet, glycogeen en koolhydraten en bepaalt daarin het \% der waterstofatomen dat door deuterium is vervangen, dan krijgt men een indruk van de snelheid waarmee zij worden gevormd.

Op soortgelijke wijze wend tevens gevonden, dat het organisme in de omzetting zijner bestanddelen veel dynamischer is dan verondersteld werd. Men voederde na honger een vet, dat veel onverzadigde vetzuren bevatte, die tevoren

2) A. KROGH: Osmotic regulation in aquatic animals, Cambridge 1939, geeft vele resultaten van permeabiliteitsproeven met zwaar water. 
chemisch met deuterium verzadigd werden. Men zou nu kunnen verwachten, dat het dier, na de doorstane honger, allereerst het opgenomen vet voor de verbranding gebruikte en zijn nog aanwezige depôtvetten onaangetast liet. Dit blijkt echter niet het geval te zijn: na enkele dagen vond men uit bepaling van het D-gehalte van het depôtvet, dat $44 \%$ van dit vet afkomstig moest zijn van het pas opgenomene. Hiervoor moet een ongeveer overeenkomstige hoeveelheid vet uit de depôts zijn gemobiliseerd voor de verbranding. Iets dergelijks is het geval, indien men voedert met aminozuren, gemerkt met deuterium, of met N15. De overeenkomstige aminozuren van het geïsoleerde spiereiwit der dieren blijken dan na enkele dagen vrij grote hoeveelheden van de isotopen te bevatten en zijn dus door de juist opgenomene gedeeltelijk vervangen of aangevuld. De isotopen blijken (in geringere mate) ook op de andere aminozuren van het eiwit te zijn overgebracht. Het is bekend dat de cellen.zelf zeer lang intact blijven. Hun samenstellende bestanddelen verwisselen dus blijkbaar zeer snel van bouwstenen, zij ,slijten" veel sneller dan men op grond van de stabiliteit der spieren en hun cellen zou verwachten. Schoenheimer ${ }^{3}$ ) heeft dan ook het samenvattende werk, waarin hij deze proeven beschreef getiteld: „The dynamic state of body constituents". Door deze resultaten is het scherpe onderscheid, dat vroeger werd gemaakt tussen bouwstofwisseling en bedrijfsstofwisseling, tussen bouwstoffen en energieleverende stoffen, vervaagd.

Door zwaar water te laten drinken kan men ook uitmaken op welke plaats bepaalde verbindingen worden opgebouwd. Een orgaan dat glycogeen opbouwt, zal veel $\mathrm{D}$ in het uit dat orgaan te isoleren glycogeen verwerkt hebben, etc. Voor de Vertebraten nu was reeds bekend, dat de spieren de voornaamste zetel zijn van glycogeenafbraak, de lever van opbouw en afbraak van het vet, terwijl opbouw van glycogeen als reservestof in de lever geschiedt. Voor Invertebraten is hiervan veel minder bekend. Aangenomen mag worden, dat ook hier de afbraak van glycogeen vnl. in de spieren plaats heef.t. Van andere processen is slechts voor enkele dieren, vooral voor Helix een dieper gaand onderzoek verricht. Dit is bij Invertebraten moeilijker, daar men hun organen niet als die der Vertebraten gemakkelijk kunstmatig doorstromen kan met bloed of Ringer, waaraan bepaalde stoffen zijn toegevoegd, om dan in het uitvloeiende bloed de reactieproducten te bepalen. Voor de stofwisseling van Helix pomatia L. is in ons laboratorium een begin gemaakt met het onderzoek der stofwisseling met behulp van zwaar water. Helix werd hiertoe gekozen, omdat zij gemakkelijk te houden is, vrij groot en wat van haar stofwisseling bekend is, het mogelijk maakt de met $\mathrm{D}_{2} \mathrm{O}$ verkregen resultaten enigszins te verifiëren. Indien men de dieren na afloop van de winterslaap hun watergehalte laat herstellen met een $\mathrm{D}_{2} \mathrm{O}$-oplossing van enige percenten, dan is het inderdaad mogelijk tot 2 weken een $\mathrm{D}_{2} \mathrm{O}$-concentratie van omstreeks $\mathrm{I} \%$ in hun weefselvloeistof

3) Al dit werk werd verricht in het biochemisch laboratorium der Columbia University (N. Y.) door Schoenheimer, RitTENBERG en hun medewerkers (Lit. nos. 3, 9, I0, II, I2). 
te handhaven. $\mathrm{Na}$ doden van de dieren en isoleren der organen blijkt, dat inderdaad de zware waterstof is opgenomen in het glycogeen en het vet van de lever en in mindere mate van de rest van het lichaam. Doet men dezelfde proef kort voor het intreden van de winterslaap of zelfs midden in de zomer dan blijkt de verwerking van de deuterium veel minder snel te gaan. Zoals voor een „koudbloedig" en vrij traag dier als Helix te verwachten was, is dit organisme dus aanzienlijk minder dynamisch dan de onderzochte vertebraten.

Ook de radioactieve isotopen zijn in de dierphysiologie veelvuldig toegepast ${ }^{4}$ ). In principe kunnen zij op dezelfde wijze gebruikt worden als de stabiele, alleen de bepaling van hun concentratie verschilt (vgl. blz. 507).

$\mathrm{Bij}$ het gebruik van radioactieve isotopen heeft men rekening te houden met de snelheid hunner ontleding, die zeer verschillend is en wordt uitgedrukt als de halveringstijd (de tijd waarin de activiteit de helft van de oorspronkelijke waarde bereikt). Deze halveringstijd is constant, daar de ontleding een monomoleculair (dus logarithmisch) proces is. Enkele veelgebruikte radioactieve isotopen (met de daarachter vermelde halveringstijden) zijn de volgende:

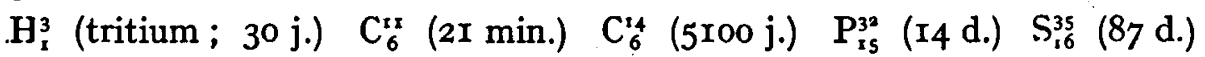
$I_{127}^{t^{31}}(8 \mathrm{~d}$.).

Is de halveringstijd zeer kort, zoals voor $\mathrm{Cl1}^{11}$, dan is de isotoop slechts voor proeven met zeer korte duur en alleen op de plaats van vervaardiging bruikbaar. Toch zijn met $\mathrm{C}^{11}$ hoogst belangrijke resultaten over de koolzuurassimilatie verkregen. Is de halveringstijd zeer lang, zoals bij $\mathrm{C}^{14}$ en $\mathrm{H}^{3}$, dan moet men zeer lang tellen om betrouwbare resultaten te krijgen. Verder speelt de prijs der stoffen (die b.v. voor $\mathrm{C}^{14}$ zeer hoog is) een rol. Van stikstof en zuurstof zijn helaas geen geschikte radioactieve isotopen bekend. De keuze tussen stabiele en radioactieve isotopen van éénzelfde element hangt dus af van de technische hulpmiddelen die men ter beschikking heeft. Bij het werken met radioactieve isotopen moeten ook beschermingsmaatregelen tegen de uitwerking van de straling op de onderzoekers genomen worden. Het Kernphysisch Instituut te Amsterdam geeft hierover nadere inlichtingen.

Radioactieve phosphor ( $\mathrm{P}^{32}$ ) is veel gebruikt voor de bestudering van de phosphaat-stofwisseling der beenderen. Zo vond men, dat been dat veel water bevat veel sneller P32 opneemt, dan waterarm been. De circulatiesnelheid in het orgaan is beslissend voor de P-opname. De snijtanden van de rat, die blijven groeien, bevatten, na voederen der dieren met gemerkt phosphaat, veel meer $\mathrm{P}^{32}$ dan de kiezen. De top van de snijtanden bevat na 3 dagen $1 / 300$ van de hoeveelheid $\mathrm{P}^{32}$, die in de basis der tanden voorkomt. Het glazuur bevat nagenoeg niets (vgl. lit. $n^{\circ} 6$ ).

4) Lit. over radioactieve isotopen nos. I, 2, 5, 6 en 7 . 
De toepassing van radioactieve phosphor in de stofwisseling van eiwit, koolhydraat en lipoiden is niet zo belangrijk als die van $\mathrm{D}, \mathrm{C}^{13}$ en $\mathrm{N}^{15}$ omdat slechts een beperkt aantal van de stoffen, die daaraan deelnemen, phosphor bevatten. Voor de phosphatide-stofwisseling is het echter te gebruiken. Zo vond Aten Jr. voor de kip, dat de phosphatiden van de eierdooier gevormd worden in de lever en vandaar door het bloed naar het zich vormende ei wonden getransporteerd. De phosphatiden van de melk ontstaan echter niet in de lever, maar in de melkklieren zelf. Met gemerkt phosphaat werden ook belangrijke resultaten bereikt bij het nagaan van de phosphaatkringloop in de spier. De complicatie van de spierstofwisseling makt het echter onmogelijk daarop nader in te gaan.

Radioactieve koolstof (C14). kan een belangrijk hulpmiddel zijn voor het onderzoek van de intermediaire stofwisseling, daar, waar men niet over een massaspectrograaf beschikt en dus de stabiele $\mathrm{C}^{13}$ niet gebruiken kan. Belangrijke resultaten werden zowel met $\mathrm{C}^{13}$ als $\mathrm{C}^{14}$ bereikt voor het volgen van de reactieweg bij de opbouw en afbraak der vetzuren. Ook hierop kan door plaatsgebrek niet worden ingegaan (zie lit. $n^{\circ} \mathrm{I} 3$ ).

Behalve voor het vaststellen van quantitatieve verschillen kunnen de radioactieve isotopen nog op andere wijze gebruikt worden. Zo kan men na inspuiting van radioactief phosphaat in de bloedbaan met een Geiger-Müller-teller qualitatief nagaan hoe snel zich dit phosphaat verspreidt en of (bv. na verwondingen) bepaalde delen van het lichaam geen deel aan de circulatie nemen. Dit wordt reeds klinisch toegepast.

Verder kan men van de concentratieverdeling van radioactieve stoffen in doorsneden van organen van planten en dieren een denkbeeld krijgen door deze doorsneden enige tijd op een phatographische plaat te leggen. Is de radioactieve isotoop op bepaalde plaatsen opgehoopt, dan uit zich dit in sterkere zwarting van de plaat. Door vergelijking met een microphoto of een macroscopisch te bestuderen coupe kan men dan omtrent de localisatie conclusies trekken. De beide laatste methoden zijn echter oriënterend, zij hebben niet de grote wetenschappelijke waarde van de daarvóór besproken methoden van onderzoek.

De toepassing van isotopen in de physiologie is nog slechts ongeveer vijftien jaar oud. Desondanks is er reeds een enorme hoeveelheid literatuur over de met deze hulpmiddelen gedane onderzoekingen in de physiologie en medicijnen verschenen. $\mathrm{Zij}$ is gecatalogiseerd in een door de Atoomcommissie der United Nations uitgegeven lijst, die enige duizenden nummers bevat. Merkwaardig is het daarom, dat de physiologische tak der Zoölogie, de vergelijkende physiologie, nog zo uiterst weinig met dit hulpmiddel gewerkt heeft. Behalve de onderzoekingen van Hevesy c.s. en van KroGH c.s. met zwaar water over de permeabiliteit en enig onderzoek in de laboratoria voor endocrinologie en vergelijkende physiologie te Utrecht (over endocrinologie resp. stofwisseling), dat nog niet wend gepubliceerd, vond ik over de stofwisseling nog enig werk 
over Tetrahymena vermeld, dat eigenlijk van microbiologische zijde afkomstig is. Naast de noodzakelijkheid van een voor alle gevallen vrij kostbare apparatuur (ook wanneer men de massaspectograaf buiten beschouwing laat!) is gebrek aan behoorlijke chemische scholing en chemisch interesse bij de meeste biologen en vooral zoölogen hiervan wel de voornaamste oorzaak. Gezien de belangrijke resultaten, die met stofwisselingsonderzoek op het gebied der vertebraten-physiologie werden bereikt, is het wel dringend gewenst, dat hierin verandering komt, wil de zoölogie hier niet bedenkelijk tekort schieten en zich een deel van haar taak door beoefenaren van andere takken van wetenschap uit handen genomen zien.

\section{LITERATUUR}

I. Aten JR., A. H. W., 1939. Dissertatie Utrecht.

2. - 1944. Vakblad voor Biologen, $\mathrm{n}^{\circ} \mathrm{g}$.

3. Вцосн, K. Some aspects of intermediary metabolism. In: D. E. GREen (1.c. onder 9) p. $29 \mathrm{I}$.

4. Hevesy, H. v., I934. Zs. physiol. Chem. 225, 28.

5. —, 1947. Advances in Enzymology 7, 111.

6. KaMEN, M. D., 1947. Radioactive tracers in biology. N. Y.

7. - 1947. Ann. Rev. of Biochem. 16, 6́31.

8. Keston, A. S., D. Rittenberg and R. Schoenheimer, 1937. Journ. biol. Chem. 122, 227.

9. RittenberG, D. and D. Shemin, 1946. Isotope technique in the study of intermediary metabolism. In: D. E. GreEN: Currents in biochemical research. Interscience Publ. Inc. N. Y. p. 261.

10. Schoenheimer, R. and D. Rittenberg, 1940. Physiol. Rev. 20, 218.

II. Schoenheimer, R., I946. The dynamic state of body constituents. Harvard University Press.

12. Stetten Jr., D., 1947. Ann. Rev. Bioch. $I$, 125.

13. Weinhouse, S., G. Medes and N. F. Floyd, I944. J. biol. Chem. I55, I43. 